\title{
Breastfeeding knowledge and practices among mothers of children younger than 2 years from a rural area in the Limpopo province, South Africa
}

\author{
S A Motadi, MSc; T Malise, BSc; L F Mushaphi, PhD \\ Department of Nutrition, School of Health Sciences, University of Venda, Thohoyandou, South Africa
}

Corresponding author: S A Motadi (Selekane.motadi@univen.ac.za)

\begin{abstract}
Background. Exclusive breastfeeding is rarely practised in most rural areas of developing countries. Poor breastfeeding practices may stem from negative attitudes or poor knowledge about the value of breastfeeding.

Objective. To determine breastfeeding knowledge and practices among mothers of infants younger than 2 years in a rural area of the Limpopo province, South Africa (SA).

Methods. A cross-sectional questionnaire-based survey was conducted among 360 women with children younger than 2 years from the Ha-Khakhu area in the Vhembe district, SA. Snowballing was used to select 360 participants.

Results. The mean age of the respondents was 29.3 (8.1) years (range 18 - 45 years). The majority (75\%) of the respondents agreed that infants should be breastfed up to the age of 6 months. Two-thirds of the respondents initiated breastfeeding within an hour of giving birth. During the time of data collection, $83 \%$ of the respondents were still breastfeeding, while $17 \%$ had stopped. The majority of the respondents $(75.8 \%)$ agreed that complementary feeding should start at the age of 6 months.

Conclusion. The respondents' breastfeeding practices did not correspond to their high level of knowledge about breastfeeding. It is recommended that health education initiatives be intensified to promote breastfeeding.
\end{abstract}

S Afr J Child Health 2019;13(3):115-119. https://doi.org/10.7196.SAJCH.2019.v13i3.1570

Appropriate feeding practices during infancy and early childhood are critical for a child's growth and development. ${ }^{[1,2]}$ Breastfeeding provides optimal and complete nutrition during the first 6 months of a baby's life, offers immunologic benefits to the baby and contributes to the psychological relationship between the mother and child. ${ }^{[3,4]}$ The World Health Organization (WHO) and the United Nations Children's Fund (UNICEF) therefore recommend that mothers breastfeed exclusively for the first 6 months of their baby's life, ${ }^{[4]}$ with nutritionally adequate and safe complementary foods being introduced along with continued breastfeeding for up to 2 years.

Although breastfeeding is widely practised in developing countries such as South Africa (SA), India and Indonesia, ${ }^{[-8]}$ previous studies have reported that exclusive breastfeeding is rare. ${ }^{[6-8]}$ The majority of mothers in these settings are reported to introduce complementary liquids within the first 7 days of the infant's life. ${ }^{[6,7]}$ This can be attributed to a lack of knowledge about infant feeding, cultural and socioeconomic factors and inconsistent advice given to new mothers..$^{[9,10-13]}$ According to Meyer et al. ${ }^{[14]}$ and Black et al. ${ }^{[15]}$ SA mothers tend to introduce food, tea and water fairly early while still breastfeeding. Infant feeding practices in SA differ from those conventionally seen in the rest of Africa, as the rate of breastfeeding is low and the use of formula milk is common. ${ }^{[14,16]}$ A study by Mushaphi et al. ${ }^{[5]}$ in villages around the Vhembe district of the Limpopo province of SA showed that 91.3\% of infants were given both breastmilk and food, and $95.5 \%$ were fed a mixture of breastmilk and water.

It is estimated that, globally, only $40 \%$ of babies are exclusively breastfed.${ }^{[17]}$ Knowledge of and a positive attitude towards breastfeeding do not necessarily translate to proper infant feeding practices, as shown by an earlier study from Nigeria. ${ }^{[18]}$ Previous studies have reported mothers' perception of not having enough breastmilk, the return to work or school and poor knowledge about breastfeeding as factors that contribute to a low rate of exclusive breastfeeding. ${ }^{[5,19-21]}$

Family and community pressure was also cited as notable reasons for mothers' early introduction of complementary foods, with previous studies showing that grandmothers or elderly women often advise mothers to introduce complementary foods as early as 1 month after birth owing to the perceived inadequate supply of breastmilk. ${ }^{[5,21,22]}$ Even if mothers have adequate knowledge about infant feeding, a lack of independent decision-making can result in poor infant feeding practices. ${ }^{[23-25]}$

The objective of this study was to determine the level of knowledge about breastfeeding and the associated practice among mothers of children younger than 24 months in rural areas of the Limpopo province, SA. It was conducted as a follow-up to a 2004 study in the province's Vhembe district, which investigated infant feeding practices and the associated nutritional status of children younger than 12 months in rural villages in this area. ${ }^{[22]}$

\section{Methods}

\section{Study population}

The study was conducted in the Ha-Khakhu village, which falls under the Mutale Municipality in Limpopo, SA, between January and August 2016. The village has an estimated total population of $3105 .{ }^{[26]}$ The area is mountainous, with several streams serving as water source although there is also some access to communal tap water.

Mothers who had breastfed their children during the first 2 years of life, either at the time of the study or before, were included in the study. Non-parent caregivers were excluded. Misconceptions such as interpreting a child's crying as a sign of breastmilk being inadequate, cultural or religious beliefs and indigenous practices that prohibit women from breastfeeding in public still exist in this village.

\section{Data collection}

Three trained fieldworkers, under the guidance of one of the researchers, conducted individual interviews with respondents in the local language (Tshivenda) to complete a set questionnaire. Each household in a village was surveyed, starting with the one next to the 
chief's kraal. The same interviewer surveyed every fourth household in the survey sequence until all households with eligible respondents were interviewed. This interviewing method was used to ensure that questions were understood correctly and so facilitate accurate data collection. Data were collected over a period of 4 months.

The questionnaire focused on respondents' sociodemographic characteristics, knowledge about breastfeeding and breastfeeding practices. Expert language practitioners independently translated the instrument from English to Tshivenda and then back to English again to ensure accuracy of translation. The questionnaire was tested in a pilot study to determine whether the questions were clearly understood by the population. To check for reliability, $10 \%$ of the completed questionnaires were randomly selected and the respondents were interviewed again a week after the initial round of data collection. This quality-control interview was conducted on different days from the initial interview and by a different interviewer than before. The quality-control data were analysed in the same way as the original data for comparison.

The researcher visited the study area three times. The first visit was to seek permission for the study from the village chief, followed by a second visit to obtain permission from eligible respondents' families. During this visit the aim of the study was explained and participants were asked to sign informed consent. The third visit was during data collection.

\section{Statistical analysis}

Statistical software (SPSS version 21, IBM Corp, USA) was used for statistical analysis. Frequency distributions were calculated for categorical data and means and standard deviations (SDs) were used for continuous data. The level of knowledge about breastfeeding was assessed using a three-point Likert scale (response options were 'agree', 'disagree' and 'do not know'). Knowledge was considered adequate if at least $60 \%$ of the questions were answered correctly.

\section{Ethical approval}

Ethical approval was obtained from the University of Venda's School of Health Sciences Higher Degree Committee (ref. no. SHS/08/ NUT/001). Permission to conduct the study was obtained from the Mutale Municipality and the Ha-Khakhu Tribal Authority. The study was conducted in accordance with the principles of the 2008 Helsinki Declaration, good clinical practices and SA law. A comprehensive written explanation of the study was given to the participants before they were asked for their signed consent.

\section{Results}

\section{Sociodemographic information}

A total of 360 respondents were included in the study. The mean age of respondents was 29.3 (8.1) years (range $18-45$ ). The mean age of infants was 12.2 (6.7) months. As shown in Table 1, 42.5\% of the respondents were married and $10 \%$ were living with a partner; $37.5 \%$ of the respondents were single. The majority of respondents were educated to Grade 8 or higher ( $40 \%$ of the participants had completed schooling between Grade 8 and Grade 11,37.5\% had completed Grade 12 and $20.8 \%$ had a tertiary qualification). A small percentage of respondents $(1.7 \%)$ did not have any formal education (Table 1).

\section{Knowledge about breastfeeding}

Table 2 presents respondents' level of knowledge about breastfeeding. Three-quarters of the respondents agreed that infants should be exclusively breastfed for 6 months; the remainder either disagreed or indicated that they did not know. The same response pattern

\begin{tabular}{|c|c|}
\hline Characteristics & $n(\%)$ \\
\hline \multicolumn{2}{|l|}{ Marital status } \\
\hline Single & $135(37.5)$ \\
\hline Married & $153(42.5)$ \\
\hline Divorced & $30(8.3)$ \\
\hline Widowed & $6(1.7)$ \\
\hline Living with a partner & $36(10.0)$ \\
\hline \multicolumn{2}{|l|}{ Educational status } \\
\hline No formal education & $6(1.7)$ \\
\hline Grade 8 - 11 & $144(40.0)$ \\
\hline Grade 12 & $135(37.5)$ \\
\hline Tertiary & $75(20.8)$ \\
\hline \multicolumn{2}{|l|}{ Household's breadwinner } \\
\hline Baby’s father & $169(47.0)$ \\
\hline Baby's mother & $125(34.7)$ \\
\hline Relatives & $66(18.3)$ \\
\hline \multicolumn{2}{|l|}{ Energy source at home } \\
\hline Wood & $109(30.3)$ \\
\hline Electricity & $251(69.7)$ \\
\hline \multicolumn{2}{|l|}{ Source of water at home } \\
\hline River & $84(23.3)$ \\
\hline Tap & $261(72.5)$ \\
\hline Dam & $15(4.2)$ \\
\hline \multicolumn{2}{|l|}{ Type of food market visited } \\
\hline Tuck shop (spaza shop) & $200(55.6)$ \\
\hline Cafe & $110(30.6)$ \\
\hline General dealer & $25(6.9)$ \\
\hline Supermarket & $25(6.9)$ \\
\hline
\end{tabular}

Table 2. Responses to questions to assess knowledge about breastfeeding among respondents $(N=360)$

\begin{tabular}{|c|c|c|c|}
\hline Questionnaire item & $\begin{array}{l}\text { Agree, } \\
n(\%)\end{array}$ & $\begin{array}{l}\text { Disagree, } \\
n(\%)\end{array}$ & $\begin{array}{l}\text { Do not know, } \\
n(\%)\end{array}$ \\
\hline An infant should be exclusively breastfed up to the age of 6 months & $270(75.0)$ & $78(21.7)$ & $12(3.3)$ \\
\hline Complementary feeding should start at the age of 6 months & $273(75.8)$ & $78(21.7)$ & $9(2.5)$ \\
\hline Infants who are breastfed have a lower risk of developing a childhood illness & $258(71.7)$ & $65(18.0)$ & $37(10.3)$ \\
\hline A mother who has insufficient milk should supplement with formula milk & $286(79.4)$ & $37(10.3)$ & $37(10.3)$ \\
\hline Infant formula takes longer to digest than breastmilk & $102(28.3)$ & $149(41.4)$ & $109(30.3)$ \\
\hline An HIV-positive mother can breastfeed exclusively & $102(28.3)$ & $109(30.3)$ & $149(41.4)$ \\
\hline Breastfeeding should continue up to the age of 2 years & $78(21.7)$ & $273(75.8)$ & $9(2.5)$ \\
\hline A woman who is breastfeeding is likely to become pregnant & $160(44.5)$ & $125(34.7)$ & $75(20.8)$ \\
\hline It is advisable for a baby to receive solid food before being breastfeed & $75(20.8)$ & $270(75.0)$ & $15(4.2)$ \\
\hline
\end{tabular}


was seen in the question regarding complementary feeding. Most participants $(71.7 \%)$ agreed that infants who are breastfed for at least 6 months are at lower risk of childhood illnesses. The majority of the respondents (79.4\%) agreed that a mother can supplement feeding with formula milk if she cannot produce enough breastmilk and slightly less than half $(41.4 \%)$ disagreed that formula milk takes longer to digest than breastmilk. A fairly large percentage of respondents (41.4\%) did not know that an HIV-positive mother can breastfeed exclusively; similar proportions agreed and disagreed with the statement (28.3\% and $30.3 \%$, respectively). Approximately threequarters of the respondents $(75.8 \%)$ indicated that breastfeeding should not have to continue up to the age of 2 years. Somewhat less than half the respondents (44.5\%) indicated that a woman who is breastfeeding is likely to become pregnant again; approximately a third disagreed with this statement and $20.8 \%$ indicated that they did not know. Three-quarters of the respondents indicated that it is not advisable that a baby should receive solid food before being breastfed.

\section{Breastfeeding practices}

All respondents initiated breastfeeding after giving birth (Table 3). Approximately two-thirds of the respondents (67.2\%) indicated that they initiated breastfeeding within an hour after delivery whereas others initiated breastfeeding either within 6 hours (1.7\%) or within a day (13.6\%) after delivery. Close to a fifth of the respondents $(17.5 \%)$ were not sure when they started breastfeeding. The majority of the respondents indicated that a healthcare worker helped them to initiate breastfeeding ( $45.8 \%$ by a nurse, $30.3 \%$ by a doctor and $22.5 \%$ by a nutritionist). Half the respondents (50\%) breastfed their babies up to three times a day, whereas $18.1 \%$ breastfeed their babies four to six times a day. The remainder (31.9\%) breastfed on demand. At the time of data collection, $83 \%$ of respondents were still breastfeeding. Among the $17 \%$ of respondents who had stopped breastfeeding, most had stopped within one $(n=16)$ or three months $(n=14)$ of delivery. A similar number had stopped breastfeeding only after 12 months $(n=19)$. Reasons for terminating breastfeeding included going back to school or work (3.9\%), not having enough milk (5.6\%) or the baby refusing to drink (1.7\%), health reasons (1.4\%) and advice by elders $(4.4 \%)$.

\section{Discussion}

The respondents showed a fairly high level of knowledge about breastfeeding. As the majority of the respondents had completed secondary or tertiary education, this knowledge level could be attributed to a high rate of literacy and education. This suggests that respondents understand and are receptive to information about breastfeeding, as received either through media channels or from health professionals during visits to an antenatal clinic.

Many women may have had support from their extended family in this setting, irrespective of their marital status. A mother is more likely to breastfeed if she receives adequate support from other family members. However, in the current study, it was observed that very few mothers breastfed exclusively: many had introduced complementary foods before the recommended age of 6 months. This observation may be attributed to a strong influence of family members in decisions around infant feeding, as seen in many rural communities in SA. ${ }^{[21,22]} \mathrm{A}$ similar observation was highlighted also by other authors, noting a lack of autonomy and decision-making power among young mothers and decisions around infant feeding involving considerable input from the extended family. ${ }^{[27,28]}$

The WHO recommends that breastfeeding should be initiated within an hour after birth. ${ }^{[1]}$ Only two-thirds of the respondents in our study were able to do this. Although breastfeeding is considered one of the most effective intervention strategies to achieve the United Nations' third and fourth millennium development goals (to achieve good health and wellbeing and to reduce child mortality, respectively), malnutrition still exists among children under two
Table 3. Responses to questions about breastfeeding practices among respondents $(N=360)$

\begin{tabular}{ll}
\hline Questionnaire item & $\boldsymbol{n}(\%)$ \\
\hline Did you initiate breastfeeding after delivery? & \\
Yes & $360(100.0)$ \\
No & $0(0.0)$
\end{tabular}

When did you initiate breastfeeding?

Within 1 hour of delivery

After 6 hours

A day after delivery

Not sure

Who helped you initiate breastfeeding?

Nurses

Doctor

Nutritionist

Other

How often do you breastfeed per day?

1 - 3 times

4- 6 times

On demand (whenever the child needs to feed) 115 (31.9)

Are you still breastfeeding?

Yes

No

When did you stop breastfeeding?*

After 2 weeks

After 1 month

After 2 - 3 months

After 4 - 5 month

$4(1.1)$

After 6 months

After $\geq 12$ months

Reason for stopping breastfeeding ${ }^{\star}$

Not producing enough milk

Baby refused to drink

$6(1.7)$

Going back to school

Health reasons

$5(1.4)$

Advice by elders

Age complementary foods were introduced (months)

$<1$

1

$19(5.3)$

2

$2-3$

$120(33.3)$

$4-5$ $149(41.4)$

Infant is not on complementary foods

Artificial feeding

Yes

$165(45.8)$

No

Reason for not breastfeeding in public

Lack of confidence

Cultural beliefs

$119(33.0)$

Religious beliefs

If you had another child, would you like to breastfeed again?

Yes

$258(71.7)$

No

Reason for not breastfeeding again

Health reason 
Table 3. (continued) Responses to questions about breastfeeding practices among respondents $(N=360)$

\begin{tabular}{|c|c|}
\hline Questionnaire item & $n(\%)$ \\
\hline Not enough milk & $56(15.6)$ \\
\hline Too painful & $16(4.4)$ \\
\hline \multicolumn{2}{|l|}{ Reason for breastfeeding again ${ }^{\ddagger}$} \\
\hline $\begin{array}{l}\text { Consider breastfeeding to be the best feeding } \\
\text { option }\end{array}$ & $70(19.5)$ \\
\hline Breastfeeding helps the child to grow well & $35(9.7)$ \\
\hline Breastfeeding is affordable & $98(27.2)$ \\
\hline Breastmilk is a source of nutrients for the baby & $55(15.3)$ \\
\hline $\begin{array}{l}{ }^{*} n / N=61 / 360 ; 17 \% . \\
{ }^{+} n / N=102 / 360 ; 28.3 \% . \\
{ }^{*} n / N=258 / 360 ; 71.7 \% .\end{array}$ & \\
\hline
\end{tabular}

years of age in SA. ${ }^{[29]}$ This may be attributed to poor infant feeding practices in developing countries, as many infants are introduced to complementary foods before the age of 6 months, increasing the risk of infections and inadequate nutritional quality. ${ }^{[8]}$

Breastmilk provides optimal and complete nutrition during the first 6 months of a baby's life. ${ }^{[30]}$ Despite the benefit of breastfeeding, very few infants are exclusively breastfed during this period. Results from our study showed that very few mothers breastfed their infants exclusively for 6 months, despite a high level of awareness around this issue. Previous studies in SA and other developing countries also showed that exclusive breastfeeding is rarely practised. ${ }^{[5,8,17,23,24]}$

Despite many respondents in our study initiating breastfeeding within an hour of delivery, a fair number started breastfeeding only later. In addition, breastfeeding on demand was rarely practised as more than two-thirds of the respondents breastfed less than six times per day. Both these factors may have contributed to mothers' perception of low milk production.

Previous studies identified going back to school or work and not having sufficient breastmilk as the main reasons for introducing complementary foods early or terminating breastfeeding. ${ }^{[5,8,21]}$ We noted similar responses in the current study.

We further also observed that several mothers were advised by elders on infant feeding practices, similar to observations from two other SA studies. ${ }^{[21,22]}$ If elderly family members are indeed still having a notable role in advising and supporting mothers on infant feeding issues, it might be wise to develop intervention programmes targeting elderly women.

Several respondents noted terminating breastfeeding because of health reasons. This may have included breast engorgement, mastitis or being HIV-positive. Almost a third of the respondents indicated that an HIV-positive mother cannot breastfeed exclusively for 6 months or longer. This worrisome proportion may be due to confusion stemming from earlier national guidelines (2001), which recommended that HIV-positive women should stop breastfeeding at 4 months. ${ }^{[19,31]}$ This message may have unintentionally spilled over to HIV-negative mothers, resulting in their giving infant formula rather than breastfeeding. HIV-negative mothers may have mistakenly understood formula milk to be a better option than breastmilk, but because of the perception that formula milk is given to babies of HIVpositive mothers, they may have rather opted for mixed feeding. Since 2011, the national policy has been that all mothers should breastfeed exclusively for the first 6 months, irrespective of their HIV status. HIV-positive mothers are advised to continue breastfeeding until their babies are 1 year old, whereas HIV-negative mothers can extend breastfeeding beyond this period. The current guideline recommends that HIV-positive women can breastfeed a baby exclusively as long as the mother receives antiretroviral or other prophylactic treatment.

\section{Study limitations}

The three-point Likert scale and response options used in this study are not considered a strong method for assessing knowledge level. Furthermore, the study focused only on the Ha-Khakhu area and findings may therefore not reflect general practices across the province

\section{Conclusion}

This study focused on infant feeding in a rural area of the Vhembe district. The findings revealed poor feeding practices, despite a high level of knowledge about breastfeeding among mothers. We suggest that the influence of elderly family members' misconceptions may be a contributing factor. Official campaigns to promote exclusive breastfeeding are recommended. Such campaigns can be supplemented with increased health education, home visits and personal communication by healthcare workers. Social media can also be used effectively to distribute information about appropriate feeding practices. To extend the findings from this study, we recommend that similar surveys are conducted in other areas in the province.

Acknowledgements. The authors thank the respondents for their participation.

Author contributions. TM was responsible for data collection and contributed to analysis. SAM was responsible for data analysis and writing the manuscript. LFM contributed to data analysis and was responsible for critical review of the manuscript and together with SAM prepared the final manuscript. All authors read and approved the manuscript for submission.

Funding. University of Venda.

Conflicts of interest. None.

1. World Health Organization (WHO). The Optimal Duration of Exclusive Breastfeeding: Report of the Expert Consultation. Geneva: WHO, 2001

2. United Nations Children's Fund (UNICEF). The state of the world's children 2009: Maternal and newborn health. New York: UNICEF, 2008. https://www. uniceforg/publications/index 47127. html (accessed 29 October 2018).

3. World Health Organization (WHO). Guidelines on HIV and Infant feeding Principles and Recommendation for Infant Feeding in the Context of HIV and a Summary of Evidence. Geneva: WHO, 2010.

4. World Health Organization/United Nations Children's Fund (WHO/UNICEF) Indicators for Assessing Infant and Young Child Feeding Practices. Washington, DC: WHO/UNICEF, 2008.

5. Mushaphi LF, Mbhenyane XG, Khoza LB, Amey AKA. Infant feeding practices of mothers and nutritional status of infants in Vhembe District in the Limpopo Province. South Afr J Clin Nutr 2008;21(2):36-41. https://doi.org/10.1080/160 70658.2008.11734159

6. Inayati DA, Scherbaum V, Purwestri RC, et al. Infant feeding practices among mildly wasted children: A retrospective study on Nias Island Indonesia. Int Breastfeed J 2012;7(1):3. https://doi.org/10.1186/1746-4358-7-3

7. Victor R, Baines SK, Agho KE, Dibley MJ. Determinants of breastfeeding indicators among children less than 24 months of age in Tanzania: A secondary analysis of the 2010 Tanzania Demographic and Health Survey. BMJ Open 2013;3(1):e001529. https://doi.org/10.1136/bmjopen-2012-001529

8. Zafar M, Fatmi Z, Shafi K. Determinants of child feeding practices in Pakistan; secondary data analysis of demographic and health survey 2006-07. J Med Nutr Nutraceut 2014;3:78-84. https://doi.org/10.4103/2278-019x.131958

9. Thulier D, Mercer J. Variables associated with breastfeeding duration. J Obstet Gynecol Neonatal Nurs 2009;38(3):259-268. https://doi.org/10.1111/j.15526909.2009.01021.x

10. Zhou Q, Younger KM, Kearney JM. An exploration of the knowledge and attitudes towards breastfeeding among a sample of Chinese mothers in Ireland. BMC Public Health 2010;10:722. https://doi.org/10.1186/1471-2458-10-722

11. Adebayo AA, Leshi OO, Sanusi RA. Breastfeeding knowledge and practice of mothers with infants less than six months old, in Kosofe Local Government of Lagos State. Niger J Nutr Sci 2014;35(2):60-67.

12. Adhikari TM. Knowledge and practice of mother regarding exclusive breastfeeding having infant at a tertiary level hospital, Kathmandu. J Nepal Paediatr Soc 2014;34(3):200-206. https://doi.org/10.3126/jnps.v34i3.12107 
13. Mallik S, Dasgupta U, Naskar S, Sengupta D, Choudbury K. Bhattacharya SK. Knowledge of breastfeeding and timely initiation of it amongst postnatal mothers: An experience from a baby-friendly teaching hospital of a metropolitan city. IOSR JDMS 2013;4(1):25-30. https://doi.org/10.9790/08530412530

14. Meyer A, Van der Spuy DA, Du Plessis LM. The rationale for adopting current international breastfeeding guidelines in South Africa. Matern Child Nutr 2007;3(4):271-280. https://doi.org/10.1111/j.1740-8709.2007.00117.x

15. Black RE, Victora CG, Walker SP, et al. Maternal and child undernutrition and overweight in low-income and middle-income countries. Lancet 2013;382(9890):427-451. https://doi.org/10.1016/s0140-6736(13)60937-x

16. Hunter-Adams J, Myer L, Rother H-A. Perceptions related to breastfeeding and the early introduction of complementary foods amongst migrants in Cape Town, South Africa. Int Breastfeed J 2016;11:29. https://doi.org/10.1186/ s13006-016-0088-3

17. World Health Organization (WHO). Babies and mothers worldwide failed by lack of investment in breastfeeding. https://www.who.int/news-room/detail/0108-2017-babies-and-mothers-worldwide-failed-by-lack-of-investment-inbreastfeeding (accessed 21/08/2018).

18. Mbada CE, Olowookere AE, Faronbi JO, et al. Knowledge, attitude and techniques of breastfeeding among Nigeria mothers from a semi-urban community. BMC Res Notes 2013;6:552. https://doi.org/10.1186/1756-05006-552

19. Doherty T, Sanders D, Jackson D, et al. Early cessation of breastfeeding amongst women in South Africa: An area needing urgent attention to improve child health. BMC Pediatr 2012;12:105. https://doi.org/10.1186/1471-2431-12-105

20. Kerr RB, Berti PR, Chirwa M. Breastfeeding and mixed feeding practices in Malawi: Timing, reasons, decision-makers, and child health consequences. Food Nutr Bull 2007;28(1):90-99. https://doi.org/10.1177/156482650702800110

21. MacIntyre UE, De Villiers FPR, Baloyi PG. Early infant feeding practices of mothers attending a postnatal clinic in Ga-Rankuwa. South Afr J Clin Nutr 2005;18(2):70-75. https://doi.org/10.1080/16070658.2005.11734042
22. Mushaphi LF, Mahopo TC, Nesamvuni CN, et al. Recommendations for infant feeding policy and programs in Dzimauli Region, South Africa: Results from the MAL-ED birth cohort. Food Nutr Bull 2017;38(3):428-440. https://doi. org/10.1177/0379572117696662

23. Arora S, McJunkin C, Wehrer J, Kuhn P. Major factors influencing breastfeeding rates: Mother's perception of father's attitude and milk supply. Pediatrics 2000;106(5):e67. https://doi.org/10.1542/peds.106.5.e67

24. Odom EC, Li R, Scanlon KS, Perrine CG, Grummer-Strawn L. Association of family and health care provider opinion on infant feeding with mother's breastfeeding decision. J Acad Nutr Diet 2014;114(8):1203-1207. https://doi. org/10.1016/j.jand.2013.08.001

25. Radwan H, Sapsford R. Maternal perceptions and views about breastfeeding practices among Emirati mothers. Food Nutr Bull 2016;37(1):73-84. https://doi. org/10.1177/0379572115624289

26. Statistics South Africa. Khakhu. http://www.statssa.gov.za/?page_ id=4286\&id=12409 (accessed 27 August 2019).

27. Pérez A, Labbok M, Queenan JT. Clinical studies of the lactation amenorrhoea method for family planning. Lancet 1992;339(8799):968-970. https://doi. org/10.1016/0140-6736(92)91538-j

28. Kramer MS, Kakuma R. The optimal duration of exclusive breastfeeding: A systematic review. Adv Exp Med Biol 2004;554:63-77.

29. Bradshaw D, Chopra M, Kerber K, et al. Every Death Counts: Saving the Lives of Mothers, Babies and Children in South Africa. Pretoria: Department of Health, 2010.

30. World Health Organization/United Nations Children's Fund (WHO/UNICEF) Global Strategy for Infant and Young Child Feeding. Geneva: WHO/UNICEF, 2003. www.who.int/nutrition/publication/infantfeeding (accessed 12 June 2017) 31. Department of Health (DoH). Protocol for Providing a Comprehensive Package of Care for the Prevention of Mother-to-Child Transmission of HIV (PMTCT) in South Africa. Pretoria: DoH, 2001.

Accepted 15 January 2019. 